\title{
Research on Building College Innovation Education Evaluation Indicator System
}

\author{
Wang Xiaobin \\ School of Economy and Management \\ Shenyang Aerospace University \\ Shenyang City, China
}

\begin{abstract}
With the constant development of the society, innovation has been widely emphasized by the society as the major force of pushing the progress of social civilization. As creative education conforms to the requirement of the times, the traditional educational evaluation has become the key to hindering the development of innovation. Therefore, a college creative education evaluation indicator system must be established. Starting from the system establishment principle, the indicators and the significance of the system has been discussed in great details in the thesis, providing some reference and practical significance for building such a system.
\end{abstract}

Keywords:-Creative education; Educational evaluation; Principle; Indicators; Significance

\section{INTRODUCTION}

Innovation is the source of power for progress of human and the major power for pushing social progress and development. All the innovations is materialized with human as the subjective, and talent is the major element for pushing innovation, especially at the advent of knowledge-based economy, it is required to cultivate a group of talents with high knowledge level and innovative spirit to realize innovation, relying on their higher theory level and practice ability. College, as the cradle for talent cultivation, has been expressly specified in our Higher Education Law to implement creative education and realize comprehensive cultivation. In this new era, we have begun to comprehensively push quality-oriented education in colleges, but we have not achieved satisfactory result under the influence of the traditional education concept and unhealthy social customs, as well as the lack of creative education evaluation mechanism. Now it has become the primary task for us to push forward creative education in higher education to integrate innovation elements into the educational system and implement creative education system from the aspects of education concept, curriculum and practice [1].

\section{THE PRINCIPLE OF ESTABLISHING COLLEGE CREATIVE}

\section{EDUCATION EVALUATION INDICATOR SYSTEM}

The most important for college creative education evaluation is to establish an evaluation indicator system. The scientific quality of the system can directly decide the later creative education evaluation. Therefore, it requires to scientifically, objectively and comprehensively reflect all the elements of college creative education. However, it is rather a difficult point to build an evaluation system conforming to requirement and faithful to reflecting creative education. Therefore, we are required to follow an objective principle to analyze and judge to solve the difficulty.

\section{A. The principle of systematicness and timeliness}

Indicator system itself includes all the aspects that creative education involves, and works through the analysis on the related principles. To form a function group with distinct gradations, the gradations shall be in a close link and consistency, and at the same time have guidance significance with the upper and lower indicators corresponding to each other. While paying attention to the internal linkage between the indicators, focus shall also be placed to the whole system function and target. The indicator system shall reflect the actual situation of the creative education in a period of time, and meanwhile keep track of its progress to better find out and solve the possible problems. In addition, the indicator system shall also conform to the change of the value concepts and be correspondingly adjusted without leading to wrong decision.

\section{B. The principle of purposiveness and scientificity}

The indicator system shall be designed with the central aim to push forward creative education any time, composed of all the major elements representing creative education and able to faithfully reflect the level of creative education from multiple angles and aspects. Set the basis for acceptance and formula derivation, rely on the principle of objectivity, scientificity and rationality to acquire the convincing evaluation results.

\section{The principle of combining identification and quantification}

Indicator system shall be designed in conformity to the principles of identification and quantification, combining identification and quantification analysis. Quantification analysis mainly aims to reveal the true color of the problems, corresponding to analysis mechanism. While missing some data qualitative indictors, scoring method can be adopted in combination with expert opinion.

\section{Principle of comparativeness and operability}

Comparativeness occurs at different time sections and between different targets, including horizontal and vertical comparison. Vertical comparison is conducted between the same targets at different time; while horizontal comparison is between different targets to find their 
common points and conclude quantize their common points in scientific and rational approach. Both are common comparison method and realize evaluation indicator system design based on their common points. In indicator system, comparability is also between the indicators on the same level---using relative value at the same measuring standard and method to try to avoid selecting the absolute value. This method can both reflect their actual conditions and find out their advantages and disadvantages, convenient to search out the weak link in creative education.

On one hand, indicator design shall have clear definition to make it easy for later data collection, at the same time consider the current scientific level to facilitate the implementation of creative education; on the other, the specific contents in the system shall be simple to reduce the trouble for the evaluation.

\section{COLLEGE CREATIVE EDUCATION EVALUATION}

\section{INDICATORS}

Based on the related literature, efforts shall be made for corresponding summary, conclusion and modification to identify the indicators of creative education management system, creative education investment and contents. Creative education evaluation indicator system has been discussed in the latter part of the thesis.

A. Comments on creative education management and system

Creative education management in colleges has a direct relation to the implementation of creative education. Creative education management mainly includes: creative education plan, creative education system and creative education management staff.

\section{1) Creative education plan}

Creative education is the future reform direction of higher education. That requires a clear developmental planning and concrete implementation step. The specific plan shall be correspondingly divided into long, intermediate and short terms, and each college shall work out a scientific and rational curriculum plan at each stage in combination with their own teaching characters, such as Creative Education Theory Teaching Plan and Creative Education Practice Teaching Plan. Furthermore, while making the specific implementation plan, try to prevent the implementation deflecting from the original direction. When necessary, identify the specific implementation details of the creative plan and put the specific implementation details to the responsible persons to improve the implementation efficiency and avoid artificial delay $[5,6]$.

\section{2) Creative education system}

Creative education system mainly includes creative education management system, creative education supervision and evaluation system, and creative education implementation examination system. A scientific and rational management system can provide system guarantee for the smooth implementation of creative education. Under the influence of environment and social demands, it requires college leaders at all level to conduct comprehensive supervision and guidance for the implementation, but shall keep the guidance and supervision within a limit, since frequent guidance and supervision can be easy to bring an uneasy and panic emotion. Furthermore, the examination requires a specific objective and the examination result shall be helpful for later work.

\section{3) Creative education management staff}

The colleges shall pay particular attention to creative education, organize strong teacher group and establish a special department. Only in this way, can we provide a steady environment to promote the implementation of creative education in colleges. Furthermore, subdivide creative education management staff in each department to make sure its implementation in all the departments and offer data material for later evaluation.

\section{B. Comments on creative education investment}

Creative education requires some conditions for implementation, either in human resource and materials. The details will be discussed from the following aspects.

\section{1) Human resource investment}

The most important point for creative education is to strengthen faculty power construction. The specific operation can be like this: selecting out the teachers with stronger innovative and teaching abilities, enhancing the teacher's salary and appropriate subsidy from government, and offering some allowance to the teachers achieving better creative education effects.

\section{2) Material investment}

While strengthening the faculty power, the colleges shall also increase the investment of material resources to offer necessary guarantee for creative education. For example, some investment can go to teaching facilities and practice sites to offer favorable conditions for later comprehensive creative teaching. In normal cases, some colleges, under the restriction of campus resources, especially the restrictions from creative education site and capital, can establish cooperation with outside enterprises and absorb their capital to makes up for the shortage and offer an employment channel for the graduates. Meanwhile, the colleges shall also set the supporting fund to offer a capital guarantee for creative education.

\section{Comments on creative education content}

\section{1) Creative curriculum}

Subject education of a college is the most fundamental part for curriculum development. Subject construction holds a particular important role for learning. A subject is the result of the wisdom of generations and built on innovation. It is required to develop creative education and do well in creative curriculum construction. The creative curriculum shall first conform to the teaching characters of the school, and take into consideration the student's personal quality and the education characters at different stages to finish curriculum design. Creative curriculum design shall consider the students' demands and solve the concrete issues in specific means. An investigation over American well-known universities has found $21 \%$ of the 5,735 courses are taken by only one student, $52 \%$ by only 8 students or even less, and $75 \%$ by 15 students or less. Furthermore, by holding various academic lectures, it can further open the vision of the teachers and students, promote the students to implement creative education and cultivate the students' quality [9]. 
2) Creative education learning ability

Creative education can be adopted in open form to shift the students from the traditional passive "storage-type" learning to the positive "output-type" exploration, offering them the chances for self-improvement, self-exploration and self-discovery, and comprehensively measure the students' quality from knowledge understanding, reception and practice. In this process, the students are required to grasp the basic knowledge and skill, and through the later practice exploration to comprehensively realize creative education and finally improve their comprehensive quality.

\section{Creative education effect evaluation}

The specific effect of creative education can be correspondingly explored through the students' subject ability, scientific activities and their rewards in the innovation competitions. The effects of the teachers in creative education can be explored from their understanding of creative education as evidenced in their thesis. Furthermore, they can also be explored from creative education organization or team rewards in competition.

\section{THE SIGNIFICANCE OF CONSTRUCTING COLLEGE CREATIVE EDUCATION EVALUATION INDICATOR SYSTEM}

In summary, college creative education has some unique characters while preserving the common points with higher education. Therefore, starting from the characters of college creative education, the thesis has the purpose of establishing college creative education evaluation indicators. Specifically, first use the effective behavior characters of creative education as the evaluation indicators of college creative education, based on the reference from the related literature and expert opinions, to identify the contents of college creative education evaluation. The related experts can sub-divide creative education into four grades: excellent, good, intermediate and poor, or achieve a more scientific and proper application through quantification. For example, use scores to replace the grades, which cannot only finish the overall and thorough evaluation, and can also find out the specific location of the problems for specific improvement to carry on the healthy and sustainable college creative education.

\section{REFERENCES}

[1] Yan Liqin, Creative Education-the Choice for Our Education Reform and Development in $21^{\text {st }}$ Century, Education Science Press, 1999

[2]Zhu Yongxin, the Theory on Creative Education, Jiangsu Press, 2001

[3] Li Guoping, Wei Hong, Vocational and Technical College Creative Education Level Evaluation indicator system research, Education and Vocation

[4] Yang Hongqing, Discussion on College Creative Education Evaluation System, Hebei Normal University of Science and Technology Journal: Social Sciences, 2005, 4(2):65

[5] Zhou yuehong, Research and Practice on Creative Education and Education Innovation, 2010 (2)

[6] Liu Xuezhong, Discussion on the Cultivation of College Creative Spirit and Ability [J], China Higher Education Research, 2007 (8).

[7] Han Cunying, Focus on Quality-oriented Education and Construct Creative Education System [J], Industry and Science Forum, 2011 (3).

[8] Xiemiao, Miaoqing, the Current Status of Chinese College Creative Education and the Problems---Taking some Science Colleges for Example [J], Southwest University of Nationality Journal (Humanities \& Social Sciences), 2009 (5).

[9] Li Zhiwen, Fangyong, Yang Yawen, Higher Education and National Creative System Construction, Elephant Press, July, 2005

[10] Xu Fangqu, Innovation and Inventive Education, January, 2001

[11]Liu Ning, Constructing Modern Education Evaluation Mechanism to Promote College Creative Talent Cultivation [J], China's Talent, 2012 (4):224-2 